\title{
Electromyography and Nerve Conduction Studies in Patients with Lumbar Spinal Stenosis: Is Neurophysiological Examination an Important Tool?
}

\author{
Marcus Sofia Ziegler ${ }^{1}$, Renata Siciliani Scalco ${ }^{2}$, Erasmo de Abreu Zardo ${ }^{1}$, Jefferson Becker ${ }^{2}$ and Irenio Gomes ${ }^{2^{*}}$ \\ ${ }^{1}$ Department of Orthopaedics \& Spine Surgery, Hospital São Lucas Pontifícia Universidade Católica do Rio Grande do Sul, Porto Alegre, Brazil \\ ${ }^{2}$ Department of Neurology, Hospital São Lucas Pontifícia Universidade Católica do Rio Grande do Sul, Porto Alegre, Brazil \\ *Corresponding author: Irenio Gomes, Hospital Sao Lucas, and Avenida Ipiranga 6690 - 3 ªndar \\ - IGG
}

Porto Alegre - RS - Brasil, CEP 90610-000, Tel: +55 (51) 3336.8153 / 3320.3000; E-mail: irenio.filho@pucrs.br

Received Date: Jan 21, 2014 Accepted Date: Apr 25, 2014 Published Date: Apr 30, 2014

Copyright: (C) 2014 Ziegler MS, et al. This is an open-access article distributed under the terms of the Creative Commons Attribution License, which permits unrestricted use, distribution, and reproduction in any medium, provided the original author and source are credited.

\begin{abstract}
Background: There is no single test that defines properly lumbar spinal stenosis (LSS) diagnosis, and diagnosis of the syndrome continues to rely on clinical judgment. LSS symptoms may be broad and may be seen in multiple disorders in elderly.

Hypothesis: To identify the role of electromyography and nerve-conduction studies on LSS diagnosis.

Materials and Methods: A cross-sectional study with prospective data collection was conducted. 31 symptomatic patients with LSS confirmed by MRI were evaluated with neurophysiology tests. We compared symptoms and neurophysiologic findings.

Results: All patients reported pain, $83.9 \%$ of patients reported it to be moderate or severe and $90 \%$ of patients took pain medication. LSS did not affect NCS or SSR. Electromyography confirmed high frequency of radiculopathy, particularly multiradiculopathy. L5 and S1 roots were the most susceptible to injuries. We also found a higher prevalence of L4 radiculopathy.

Discussion: Correlating electromyography with clinical findings, we found that the clinical presentation, the most important starting point of an evaluation, is poor in terms of identifying radiculopathy, a frequent consequence of LSS. For this reason, we suggest that electromyography may play an important role as a diagnostic tool, being useful in determining when symptoms are neurogenic in nature. In addition, it may serve to focus treatment only in the area where it is really necessary.
\end{abstract}

Keywords: Lumbar spinal stenosis; Electromyography; Sympathetic skin response; Nerve conduction studies; Radiculopathy

\section{Introduction}

Lumbar spinal stenosis (LSS) refers to a spinal canal narrowing compressing the spinal cord and its nerves at the level of the lumbar vertebra $[1,2]$. Symptoms include leg weakness, back pain, and rarely sphincter dysfunction [3-6]. Some patients are asymptomatic [7]. This constellation of symptoms may also be identified in elderly with different conditions rather than LSS. Consequently clinical suspected LSS should be confirmed by a diagnostic exam. Unfortunately there is no single test that strongly defines LSS diagnosis. LSS diagnosis is made through a complete assessment that combines history, physical exam, neurophysiology and imaging. Magnetic resonance imaging (MRI) is used as the preferred imaging test for assessing the stenosis $[1,3]$, but it is not used as a screening tool and it does not evaluate nerve function. Despite advances in the clinical understanding of LSS and improvements in imaging techniques, it occasionally remains difficult to diagnose this disorder [7-11]. MRI does not define properly which part of the nervous system is being affected by the stenosis (spine, nerves or both). For this reason the aim of this study is to identify the role of neurophysiology study on LSS.

\section{Methods}

A cross-sectional study with prospective data collection was performed at Hospital São Lucas Pontifícia Universidade Católica do Rio Grande do Sul (HSL-PUCRS) during 8 months. Inclusion criteria was symptomatic patients that filled the MRI diagnostic criteria for LSS $[7,12]$. Exclusion criteria were people younger than 60 years of age, previous history of diabetes mellitus, alcoholism and other confirmed neurologic disorders. The project was approved by local Research and Ethics Committee and informed consent was obtained.

Neurophysiology evaluation (Viasys Synergy equipment)included bilateral (i) antidromic sensory nerve conduction study (SNCS) of the superficial peroneal and sural nerves, (ii) motor nerve conduction study of the common peroneal nerve and tibial nerve, (iii) concentric needle electromyography (EMG) of the iliacus (L2-L3), vastusmedialis and adductor magnus (L4), tibialis anterior and gluteus medius (L5) 
Citation: Ziegler MS, Scalco S, Zardo EDA, Becker J and Gomes I (2014) Electromyography and Nerve Conduction Studies in Patients with Lumbar Spinal Stenosis: Is Neurophysiological Examination an Important Tool?. J Neurol Neurophysiol 5: 1000203. doi: $10.4172 / 2155-9562.1000203$

Page 2 of 4

and medial gastrocnemius and biceps femoris (short head) muscles (S1); (iv) sympathetic skin response (SSR) recorded in the region of the right plantar and stimulation in the left tibial nerve $[13,14]$. SNCS of the superficial peroneal and sural nerves, and motor conduction studies of the deep peroneal and tibial nerves were compared with 4 control groups (one for each nerve) composed of 45 men and 105 women, balanced by age group, randomly taken from the HSL-PUCRS database. Radiculopathy was defined as the presence of the following in at least 2-limb muscles innervated by the same nerve root: huge MUAPs, fibrillation potentials, positive sharp waves and reduced recruitment.

Data was analyzed using SPSS version 17.0.The means for age and neurophysiological parameters established through neurophysiological study were compared between participants and control groups using an independent samples t-test taking into account the similarity between variances verified by Levene's test. The frequencies of imaging and clinical variables (categorical) were compared between participants with and without an electromyography diagnosis of radiculopathy using Pearson's chi-squared test. $\mathrm{P}$ values less than or equal to $5 \%$ were considered to be significant.

\section{Results}

We analysed 31 patients: 9 (29\%) men and 22 (71\%) women. Age varied from 60 to 84 years with a mean and standard deviation of $71 \pm$ 8.2. All patients reported pain ( $90 \%$ complained of back pain and $81 \%$ complained of sciatic pain). Bilateral sciatic pain was seen in $56 \%$. Almost $40 \%$ of patients were unable to walk 100 meters because of the pain. Use of pain relief drugs was seen in $90 \%$ of elderly, $25 \%$ of those used non-steroidal anti-inflammatory drugs, 32\% narcotics and $43 \%$ corticosteroids.

Regarding MRI findings, compression was by the vertebra in $29 \%$ of patients, by the intervertebral space in $61 \%$ and by both in $10 \%$. Only one patient had compression by the vertebral body (anterior). The remaining vertebral compressions were by the arch, with $5(16 \%)$ at only one level and $6(19 \%)$ at two or more levels. Sixteen patients (52\%) had stable compression of the intervertebral space, mostly of lateral $(23 \%)$ or centrolateral (26\%) location. Unstable intervertebral involvement was seen in $16 \%$ of patients with most being centrolateral in location. The area of stenosis was $16 \%$ in the entrance zone, $52 \%$ in the mid-zone, and $32 \%$ in the exit zone.

Regarding nerve conduction studies (NCS), Table 1 compares latency, amplitude and conductive velocity between participants and controls. The sural nerve latency was smaller in LSS patients comparing to normal controls $(\mathrm{P}<0.01)$. Superficial peroneal nerve conductive velocity was slightly greater in LSS patients comparing to normal controls. Both findings had no clinical significance. Noneparticipant had absent SSR and only 4 participants had amplitude of less than $300 \mu \mathrm{V}$, with 3 of these having multiradicular lesions. The latency ranged from 1.3 to $3.5 \mathrm{~ms}$, with a mean of $2.2 \mathrm{~ms}$ and standard deviation of $0.5 \mathrm{~ms}$. The amplitude ranged from 60 to $4129 \mu \mathrm{V}$, with a mean of $1056 \mu \mathrm{V}$ and standard deviation of $952 \mu \mathrm{V}$. No difference of the mean amplitude was seen between participants and the control group $(\mathrm{P}>0.05)$.

\begin{tabular}{|c|c|c|c|c|}
\hline \multirow{2}{*}{$\begin{array}{l}\text { Neurophysiologic } \\
\text { Parameters }\end{array}$} & \multicolumn{2}{|c|}{ Patients } & Controls & $\mathbf{P}$ \\
\hline & $\mathbf{N}$ & $m \pm s d$ & $N_{s d}^{m \pm}$ & \\
\hline
\end{tabular}

\begin{tabular}{|c|c|c|c|c|c|c|}
\hline & \multicolumn{6}{|c|}{ Sensory Nerve Conduction } \\
\hline & \multicolumn{6}{|l|}{ Superficial fibular } \\
\hline & Latency (ms) & 58 & $2.68 \pm 1.51$ & 141 & $2.71 \pm 0.45$ & $\begin{array}{l}0.87 \\
7\end{array}$ \\
\hline & Amplitude $(\mu \mathrm{V})$ & 58 & $\begin{array}{ll}12.00 & \pm \\
5.07 & \end{array}$ & 141 & $\begin{array}{ll}11.59 & \pm \\
6.65 & \end{array}$ & $\begin{array}{l}0.67 \\
9\end{array}$ \\
\hline & $\begin{array}{l}\text { Conduction velocity } \\
(\mathrm{m} / \mathrm{s})\end{array}$ & 58 & $\begin{array}{ll}48.02 & \pm \\
5.73 & \end{array}$ & 141 & $\begin{array}{ll}45.72 & \pm \\
4.13 & \end{array}$ & $\begin{array}{l}0.00 \\
7\end{array}$ \\
\hline & \multicolumn{6}{|c|}{ Sural } \\
\hline & Latency (ms) & 21 & $2.93 \pm 0.58$ & 121 & $3.29 \pm 0.56$ & $\begin{array}{l}0.00 \\
9\end{array}$ \\
\hline & Amplitude $(\mu \mathrm{V})$ & 21 & $\begin{array}{ll}12.41 & \pm \\
3.11 & \end{array}$ & 121 & $\begin{array}{ll}11.91 & \pm \\
6.08 & \end{array}$ & $\begin{array}{l}0.57 \\
5\end{array}$ \\
\hline & $\begin{array}{l}\text { Conduction velocity } \\
(\mathrm{m} / \mathrm{s})\end{array}$ & 21 & $\begin{array}{ll}48.47 & \pm \\
4.66 & \end{array}$ & 121 & $\begin{array}{l}45.81 \quad \pm \\
3.90\end{array}$ & $\begin{array}{l}0.00 \\
6\end{array}$ \\
\hline & \multicolumn{6}{|c|}{ Motor Nerve Conduction } \\
\hline & \multicolumn{6}{|l|}{ Deep fibular } \\
\hline & Distal latency (ms) & 52 & $4.07 \pm 1.10$ & 150 & $3.93 \pm 0.73$ & $\begin{array}{l}0.40 \\
2\end{array}$ \\
\hline & Distal amplitude (mV) & 52 & $4.05 \pm 1.90$ & 150 & $4.34 \pm 2.08$ & $\begin{array}{l}0.36 \\
4\end{array}$ \\
\hline & $\begin{array}{l}\text { Proximal amplitude } \\
(\mathrm{mV})\end{array}$ & 52 & $3.56 \pm 1.77$ & 150 & $3.92 \pm 1.94$ & $\begin{array}{l}0.23 \\
8\end{array}$ \\
\hline & $\begin{array}{l}\text { Conduction velocity } \\
(\mathrm{m} / \mathrm{s})\end{array}$ & 52 & $\begin{array}{ll}47.87 & \pm \\
6.28 & \end{array}$ & 150 & $\begin{array}{ll}46.40 & \pm \\
4.08 & \end{array}$ & $\begin{array}{l}0.12 \\
2\end{array}$ \\
\hline & \multicolumn{6}{|c|}{ Tibial } \\
\hline & Distal latency (ms) & 53 & $3.92 \pm 0.80$ & 150 & $3.96 \pm 0.71$ & $\begin{array}{l}0.72 \\
8\end{array}$ \\
\hline & Distal amplitude (mV) & 53 & $8.88 \pm 4.22$ & 150 & $\begin{array}{ll}10.03 & \pm \\
3.69 & \end{array}$ & $\begin{array}{l}0.06 \\
3\end{array}$ \\
\hline
\end{tabular}

Table 1. Nerve conduction parameters

Radiculopathy was found in $64.5 \%$. Impairment of one root was seen in $30 \%$ of patients with radiculopathy whilst $40 \%$ had four or more roots with lesions. The radicular lesion was bilateral in $55 \%$ of the cases and the frequency between both sides was similar. The most often affected roots were L5 (60\% on the right, and $70 \%$ on the left) and $\mathrm{S} 1(70 \%$ on the right, and $60 \%$ on the left).

Table 2 compared radiculopathy frequency with clinical and radiological findings. The frequency of radiological radiculopathy was $33 \%, 74 \%$ and $100 \%$ for those with compression of the spinal canal by the vertebra, by the intervertebral space, and by both respectively $(\mathrm{P}=0.046)$.

\begin{tabular}{|c|c|c|c|c|c|}
\hline Variable & $\begin{array}{l}\text { Without } \\
\mathrm{N}(\%)\end{array}$ & Radiculopathy & $\begin{array}{l}\text { With } \\
N(\%)\end{array}$ & Radiculopathy & $\mathbf{P}$ \\
\hline \multicolumn{6}{|l|}{ Gender } \\
\hline Male & $2(22.2)$ & & $7(77.8)$ & & \multirow{2}{*}{0.429} \\
\hline Female & $9(40.9)$ & & $13(59.1)$ & & \\
\hline
\end{tabular}


Citation: Ziegler MS, Scalco S, Zardo EDA, Becker J and Gomes I (2014) Electromyography and Nerve Conduction Studies in Patients with Lumbar Spinal Stenosis: Is Neurophysiological Examination an Important Tool?. J Neurol Neurophysiol 5: 1000203. doi: $10.4172 / 2155-9562.1000203$

Page 3 of 4

\begin{tabular}{|l|l|l|l|l|}
\hline \multicolumn{4}{|l|}{ Age range (years) } & \multirow{2}{*}{0.468} \\
\hline & $60-69$ & $3(23.1)$ & $10(76.9)$ & \\
\hline $70-79$ & $5(45.5)$ & $6(54.5)$ & \\
\hline & $80+$ & $3(42.9)$ & $4(57.1)$ & \\
\hline
\end{tabular}

Lumbar pain

\begin{tabular}{|c|c|c|c|}
\hline Yes & $11(39.3)$ & $17(60.7)$ & \multirow{2}{*}{0.535} \\
\hline No & $0(0.0)$ & $3(100.0)$ & \\
\hline \multicolumn{4}{|c|}{ Sciatic pain } \\
\hline Yes & $8(32.0)$ & $17(68.0)$ & \multirow{2}{*}{0.638} \\
\hline No & $3(50.0)$ & $3(50.0)$ & \\
\hline
\end{tabular}

Asymmetric reflex

\begin{tabular}{|l|l|l|l|l|}
\hline Yes & $11(39.3)$ & $17(60.7)$ & \multirow{2}{*}{0.535} \\
\cline { 1 - 3 } No & $3(42.9)$ & $4(57.1)$ & \\
\hline
\end{tabular}

Significant weakness

\begin{tabular}{|l|l|l|l|l|}
\hline & Yes & $10(34.5)$ & $19(65.5)$ & \multirow{2}{*}{1.000} \\
\cline { 1 - 3 } & No & $1(50.0)$ & $1(50.0)$ & \\
\hline
\end{tabular}

Alteration in sensitivity

\begin{tabular}{|c|c|c|c|}
\hline No & $9(40.9)$ & $13(59.1)$ & \multirow{3}{*}{0.544} \\
\hline L2-L4 & $1(33.3)$ & $2(66.7)$ & \\
\hline L5-S1 & $1(16.7)$ & $5(83.3)$ & \\
\hline
\end{tabular}

Classification by MR imaging

\begin{tabular}{|l|l|l|l|}
\hline Vertebra & $6(66.7)$ & $3(33.3)$ & \\
\cline { 1 - 2 } $\begin{array}{l}\text { Intervertebr } \\
\text { al space }\end{array}$ & $5(26.3)$ & $14(73.7)$ & 0.046 \\
\cline { 1 - 2 } Combined & $0(0.0)$ & $3(100.0)$ & \\
\hline
\end{tabular}

Vertebral arch involvement

\begin{tabular}{|l|l|l|l|l|}
\hline 1 level & $4(80.0)$ & $1(20.0)$ & \multirow{2}{*}{0.242} \\
\cline { 1 - 3 } $2+$ levels & $2(33.3)$ & $4(66.7)$ & \\
\hline
\end{tabular}

Intervertebral space involvement

\begin{tabular}{|l|l|l|l|l|}
\hline Central & $0(0.0)$ & $2(100.0)$ & \\
\hline & Lateral & $1(12.5)$ & $7(87.5)$ & 0.342 \\
\hline $\begin{array}{l}\text { Centrolater } \\
\text { al }\end{array}$ & $4(36.4)$ & $7(63.6)$ & \\
\hline
\end{tabular}

Spinal stability

\begin{tabular}{|c|c|c|c|}
\hline Stable & $3(18.8)$ & $13(81.2)$ & \multirow{2}{*}{0.553} \\
\hline Unstable & $2(40.0)$ & $3(60.0)$ & \\
\hline \multicolumn{4}{|c|}{ Region of stenosis } \\
\hline $\begin{array}{l}\text { Entrance } \\
\text { zone }\end{array}$ & $2(40.0)$ & $3(60,0)$ & 0.456 \\
\hline
\end{tabular}

\begin{tabular}{|c|c|c|}
\hline Mid-zone & 7 (43.8) & $9(56.2)$ \\
\hline Exit zone & $2(20.0)$ & $8(80.0)$ \\
\hline
\end{tabular}

Table 2. Clinical, EMG and imaging findings in LSS patients.

\section{Discussion}

A cross-sectional study was performed to identify the role of neurophysiology study in LSS. To address this question we correlated neurophysiology findings, LSS symptoms and MRI abnormalities. We believe that our findings are relevant although we also consider that it is important to repeat this study in a larger population.

We found LSS to be more common in women. There is no consensus regarding the exact LSS gender ratio. A higher proportion of female patients with lateral stenosis (68\%) was described in 1993 as opposed to central stenosis where just $46 \%$ were women [15]. On the other hand an equal gender distribution has also been reported previously [16].Pain was considered a major feature as $83.9 \%$ of patients reported moderate or severe pain, and the vast majority of patients took pain relief medication. Based on the sample analyzed, pain was the most common symptom of LSS, although the exact prevalence of pain among LSS patients is not clear from the literature.

In relation to the neurophysiology findings, nerve conduction study (NCS) was normal in LSS patients. Although patients have normal test, we agree that NCS should be performed in patients with LSS symptoms as it is an important diagnostic tool to evaluate the presence of other neuromuscular conditions [5,13,17-19].It has been previously suggested that SSR could be important in diagnosing spinal stenosis [23].This present study is the first to analyse SSR in LSS and found that the SSR was also normal in the LSS patients. We conclude that lumbar stenosis does not affect SSR although we also consider that it is important to repeat this study in a larger population.

An interesting finding of this research was the EMG abnormalities. Our study showed a high frequency of radiculopathy particularly multiradiculopathy. L5 and S1 roots were the most susceptible to injuries and the prevalence of L5 and S1 radiculopathies were almost the same. We also found a high prevalence of L4 radiculopathy. It has been described, when considering MRI abnormalities, that L4-5 is the commonest involved level in LSS, followed by L5-S1 and L3-4 [7]. Maybe it could reflect that MRI is not a sensitive method to assess radiculopathy. Similar results based on EMG were also found in this study confirming that this may be a reliable diagnostic tool for root assessment in LSS. According to the literature, LSS is the most common cause of polyradiculopathy. Spondylosisis a more common cause of root disease in older adults [20].Further researches should assess if EMG may be of assistance in grading the severity of LSS, especially when multiradiculopathy is a factor, as it gives an objective indication of root injury. In accordance with Nardinet al. we believe that EMG and MRI are complementary tools for the evaluation of radiculopathy [21].

Regarding MRI findings, the majority of patients with radiculopathy had compression of the intervertebral space or a combined compression - type B and C according to Landim (2008) [22]. The only variable that showed a significant association with EMG diagnosis of radiculopathy was the compression of intervertebral space. We do not believe that MRI could replace the EMG as diagnostic tool for radiculopathy although this study was not designed to address this question. 
Citation: Ziegler MS, Scalco S, Zardo EDA, Becker J and Gomes I (2014) Electromyography and Nerve Conduction Studies in Patients with Lumbar Spinal Stenosis: Is Neurophysiological Examination an Important Tool?. J Neurol Neurophysiol 5: 1000203. doi: $10.4172 / 2155-9562.1000203$

Page 4 of 4

Another important finding of this study is the comparison between clinical variables and EMG. It showed that medical history is not a good indicator of radiculopathy when the major complain is back pain. Sciatic pain is also a poor indicator of the disease as half of people who did not complain of sciatic pain had a diagnostic EMG for radiculopathy. All clinical variables based on the $\mathrm{P}$ value were not significant.

Summarizing, there is currently no specific test that gives an accurate diagnosis of LSS. This research showed that LSS clinical presentation - the most important starting point of a clinical evaluation - was poor in terms of identifying radiculopathy caused by LSS. Although EMG does not help as a diagnostic tool for LSS, it may confirm radiculopathy even in patients with no classical symptoms of root involvement. Future research could correlate EMG and treatment approach as EMG may add by defining which root is compromised, which help grading disease severity and guiding surgical can approach, particularly if a diffuse MRI abnormality is present.

\section{References}

1. Siebert E, Prüss H, Klingebiel R, Failli V, Einhäupl KM, et al. (2009) Lumbar spinal stenosis: syndrome, diagnostics and treatment. Nat Rev Neurol 5: 392-403.

2. Miyamoto M, Genbum Y, Ito H (2002) [Diagnosis and treatment of lumbar spinal canal stenosis]. J Nippon Med Sch 69: 583-587.

3. Filho TEPB, Júnior RB, Cristante AF, Araújo MP (2009) Colunatoracolombar: síndromesdolorosas. In: Hebert S, Filho TEPB, Xavier R, Pardini Jr AG., editors. Ortopedia e TraumatologiaPrinícios e Prática, (4thedn). Porto Alegre: Artmed 122-130.

4. Chiodo A, Haig AJ, Yamakawa KS, Quint D, Tong H, et al. (2008) Magnetic resonance imaging vs. electrodiagnostic root compromise in lumbar spinal stenosis: a masked controlled study. Am J Phys Med Rehabil 87: 789-797.

5. Joaquim AF, Sansur CA, Hamilton DK, Shaffrey CI (2009) Degenerative lumbar stenosis: update. ArqNeuropsiquiatr 67: 553-558.

6. Sheehan JM, Shaffrey CI, Jane JA Sr (2001) Degenerative lumbar stenosis: the neurosurgical perspective. ClinOrthopRelat Res : 61-74.

7. Curlee PM (2008) Spinal Stenosis. In: Canale ST, Beaty JH, editors Campbell's Operative Orthopaedics, 11 ed. Mosby :2274-2288.

8. Sheehan NJ (2010) Magnetic resonance imaging for low back pain: indications and limitations. Ann Rheum Dis 69: 7-11.
9. Boden SD, Davis DO, Dina TS, Patronas NJ, Wiesel SW (1990) Abnormal magnetic-resonance scans of the lumbar spine in asymptomatic subjects. A prospective investigation. J Bone Joint Surg Am 72: 403-408.

10. Amundsen T, Weber H, Lilleås F, Nordal HJ, Abdelnoor M, et al. (1995) Lumbar spinal stenosis. Clinical and radiologic features. Spine (Phila Pa 1976) 20: 1178-1186.

11. de Graaf I, Prak A, Bierma-Zeinstra S, Thomas S, Peul W, et al. (2006) Diagnosis of lumbar spinal stenosis: a systematic review of the accuracy of diagnostic tests. Spine (Phila Pa 1976) 31: 1168-1176.

12. Lurie JD, Tosteson AN, Tosteson TD, Carragee E, Carrino JA, et al. (2008) Reliability of readings of magnetic resonance imaging features of lumbar spinal stenosis. Spine 33: 1605-1610.

13. Amato AA, Russell JA (2008) Neuromuscular Disorders. United States of America: McGraw-Hill Professional.

14. Dumitru D, Amato AA,Zwarts M (2002) Electrodiagnostic Medicine. Philadelphia: Hanley \&Belfus.

15. Jönsson B, Strömqvist B (1993) Symptoms and signs in degeneration of the lumbar spine. A prospective, consecutive study of 300 operated patients. J Bone Joint Surg Br 75: 381-385.

16. Getty CJ (1980) Lumbar spinal stenosis: the clinical spectrum and the results of operation. J Bone Joint Surg Br 62-62B: 481-5.

17. Haig AJ, Tong HC, Yamakawa KS, Quint DJ, Hoff JT, et al. (2005) The sensitivity and specificity of electrodiagnostic testing for the clinical syndrome of lumbar spinal stenosis. Spine (Phila Pa 1976) 30: 2667-2676.

18. Aminoff MJ (1998) Electromyography in clinical practice. New York: Churchill Livingstone.

19. Mansukhani KA, Doshi BH (2008) Interpretation of electroneuromyographic studies in diseases of neuromuscular junction and myopathies. Neurol India 56: 339-347.

20. Amato AA, Russell JA (2008) Radiculopathies, Plexopathies, and Mononeuropathies of the Lower Extremity. In: Amato AA, Russell JA, editors. Neuromuscular Disorders, 1st ed. United States of America: McGraw-Hill Professional 415-455.

21. Nardin RA, Patel MR, Gudas TF, Rutkove SB, Raynor EM (1999) Electromyography and magnetic resonance imaging in the evaluation of radiculopathy. Muscle Nerve 22: 151-155.

22. Landim E (2008) A new classification for lumbar stenosis. Coluna/ Columna 7: 97-100.

23. Ogura T, Kubo T, Lee K, Katayama Y, Kira Y, et al. (2004) Sympathetic skin response in patients with spinal cord injury. J OrthopSurg (Hong Kong) 12:35-39. 